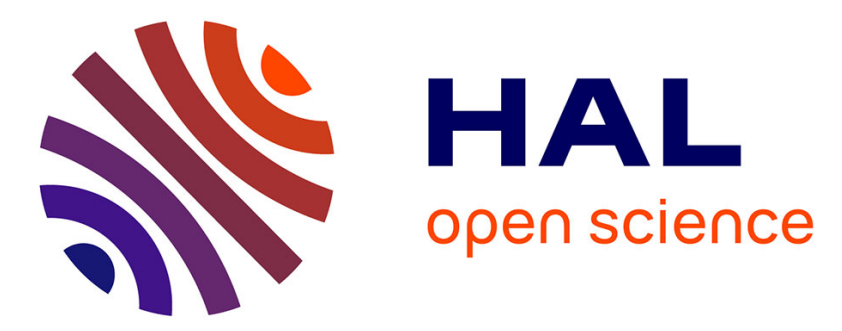

\title{
Internet-based technologies to improve cancer care coordination: Current use and attitudes among cancer patients
}

Anne Girault, Marie Ferrua, Benoît Lalloué, Claude Sicotte, Aude Fourcade, Fatima Yatim, Guillaume Hébert, Mario Di Palma, Etienne Minvielle

\section{To cite this version:}

Anne Girault, Marie Ferrua, Benoît Lalloué, Claude Sicotte, Aude Fourcade, et al.. Internet-based technologies to improve cancer care coordination: Current use and attitudes among cancer patients. European Journal of Cancer, 2015, 51 (4), pp.551 - 557. 10.1016/j.ejca.2014.12.001 . hal-01438096

\section{HAL Id: hal-01438096 https://hal.science/hal-01438096}

Submitted on 17 Jan 2017

HAL is a multi-disciplinary open access archive for the deposit and dissemination of scientific research documents, whether they are published or not. The documents may come from teaching and research institutions in France or abroad, or from public or private research centers.
L'archive ouverte pluridisciplinaire HAL, est destinée au dépôt et à la diffusion de documents scientifiques de niveau recherche, publiés ou non, émanant des établissements d'enseignement et de recherche français ou étrangers, des laboratoires publics ou privés. 
Anne Girault, Marie Ferrua, Benoît Lalloué,Claude Sicotte, Aude Fourcade, Fatima Yatim, Guillaume Hébert, Mario Di Palma, Etienne Minvielle

Original research article

\section{Internet-based technologies to improve cancer care coordination: Current use and attitudes among cancer patients}

\section{Abstract}

Background: The uses of internet-based technologies (e.g. patient portals, websites and applications) by cancer patients could be strong drive for change in cancer care coordination practices. The goal of this study was to assess the current utilization of internetbased technologies (IBT) among cancer patients, and their willingness to use them for their health, as well as analyze the influence of socio-demographics on both aspects. Methods: A questionnaire-based survey was conducted in June 2013, over seven non-consecutive days within seven outpatient departments of Gustave Roussy, a comprehensive cancer center ( $\approx 160000$ consultations yearly), located just outside Paris. We computed descriptive statistics and performed correlation analysis to investigate patients' usage and attitudes in correspondence with age, gender, socioeconomic status, social isolation, and place of living. We then conducted multinomial logistic regressions using R. Results: The participation level was $85 \%(n=1371)$. The median age was $53.4 .71 \%$ used a mobile phone everyday and $93 \%$ had access to Internet from home. Age and socioeconomic status were negatively associated with the use of IBT $(p<0.001)$. Regarding patients' expected benefits, a wide majority valued its use in health care, and especially, the possibility to enhance communication with providers. $84 \%$ of patients reported feeling comfortable with the use of such technologies but age and socioeconomic status had a significant influence. Conclusion: Most patients used IBTs every day. Overall, patients advocated for an extended use of IBT in oncology. Differences in perceived ease of use corresponding to age and socioeconomic status have to be addressed. 


\section{Introduction}

Today, a number of important changes are altering cancer care delivery. We observe an increase in outpatient care services coupled with a decrease in inpatient care. Clinical advances have improved the survival rates for most cancers, leading health professionals to treat cancer as a chronic disease. With oral therapies, more cancer patients, even during active treatment, can also be cared for from home. These changes, which could save important costs in a context of high financial constraints, are, however, challenging current cancer care coordination practices [1], [2]. Better coordination between patients and providers and among providers, is utterly needed to ensure adequate follow-up of patients. Internet-based technologies (IBT) such as patient portals, websites and applications, managed by healthcare institutions, have therefore been recognized as a significant lever to improve cancer care coordination practices[3].

A recent systematic review conducted in the US, in 2013 , highlighted the four recurrent components of cancer coordination: $1 /$ roles and models for communication and transfer of care between primary care physicians and oncologists during active treatment and survivorship; 2/ care navigation through designated personnel or telecommunication processes among care team members; 3 / treatment summaries and survivorship care plans; and $4 /$ multidisciplinary communication accompanying patient and practice management within the framework of the Chronic Care Model [4], [5].

In light of this, IBT can bring valuable opportunities to improve cancer care coordination by enhancing patient-provider communication, by monitoring adverse events and by providing better patient follow-up at distance [6], [7].

However, more evidence is needed regarding cancer patient's current use and willingness to use IBT to monitor their health. First, it is important to know more about their physical 
connectivity to Internet. In the general population, although physical connectivity to Internet remains a concern, the "digital divide" is narrowing. For instance, in the EU28, $79 \%$ of households had access to the internet in 2013 and $76 \%$ had a broadband internet connection, compared with $55 \%$ and $42 \%$ respectively in 2007 [8]. Nevertheless, cancer patients can have specific characteristics compared to the general population, especially as cancer patients tend to be older [9]. Secondly, it is required to understand the attitudes regarding computers, internet and applications as they may play an important role in the willingness to use them for their health [10], [11]. Thirdly, the question of the influence of social inequalities has to be addressed. In the literature, the most frequent sociodemographic factors found to be predictors of IBT use were age, education, socioeconomic status, gender, place of living and social isolation [12]-[17].

\section{Scope of the study}

Based on a patient survey, the three objectives of the study were:

- To understand the current level of use of IBT (computers, tablets, mobile phones and smartphones)

- To assess the intention to use IBT for their health

- To determine what socio-demographic criteria could be predictors of the use and willingness to use new IBT in healthcare

\section{Patients and Methods}

A questionnaire-based survey was conducted in June 2013 in Gustave Roussy within seven outpatient departments (medical oncology for prostate, breast, skin, head and neck, endocrine, gastric and cervical cancers, radiotherapy, radiology, anesthesia, hematology). 


\section{Setting}

\section{Gustave Roussy}

Gustave Roussy is the largest comprehensive cancer center in Europe, and is located in the suburbs of Paris. The hospital cares for about 50,000 cancer patients annually. Patients come from the full range of socioeconomic backgrounds.

\section{Project Scope}

This study was conducted in response to the needs of the CAPRI (Cancer, Parcours de Soins, Région lle de France) project that is in the process of being implemented at Gustave Roussy (2013-2016). Its objective is to improve the quality of care and coordination for cancer patients treated in the hospital through the implementation of a coordination platform based on two nurse navigators and a dedicated online portal in order to improve the coordination of patients across the care continuum.

\section{Questionnaire design}

The questionnaire was built upon a preliminary literature review conducted between January and June 2013 on Google Scholar ${ }^{\mathrm{TM}}$, Web of knowledge ${ }^{\mathrm{TM}}$ and Pubmed ${ }^{\mathrm{TM}}$. It consisted of a total of 38 multiple-choice questions and one open question. The questionnaire comprised three parts: (i) Use of internet through computers, mobile phones and tablets (ii) Willingness to use information technologies for their health, (iii) Socio-demographics.

Survey items asked for patients' use of information technologies (computer, mobile phones, tablets) for accessing to the Internet and their intention to use these devices for health care.

To investigate whether different groups within the population had different patterns of use, we selected five socio-demographic variables including age, gender, socioeconomic status (based on employment status), number of people in the household, and the type of locality they live in (rural/urban). Intention to use IBT for different services in health was measured 
using a 5-point Likert scale ranging from 1 (definitely not useful) to 5 (definitely useful). The services were: provision of information about disease and treatment, provision of information about care and support, peer communication in support groups, patient-provider communication by e-consultation, autonomous symptom monitoring, and symptom monitoring with e-monitoring of the care provider.

To ensure validity in this method, we tested the questionnaire through face validity, using two complementary approaches. First, we gathered a panel of experts (2 physicians, 2 pharmacists, 2 nurses and 2 senior researchers) to evaluate the questionnaire. Following their suggestions, minor modifications were made. Second, content validity was then checked by passing the questionnaire to a group of patients $(n=20)$ within Gustave Roussy to ensure the questions were relevant and properly answered by patients. Different adjustments were made after analysis of the comments. Eventually, the final draft of the questionnaire was reviewed in consultation with a statistician to ensure that the questions could be coded appropriately for data analysis.

\section{Data collection}

\section{Patient eligibility}

Patients over the age of 18 were asked by front desk staff if they were willing to complete an anonymous questionnaire regarding their current use and attitudes toward new information technologies while waiting for their appointment. The medical staff of Gustave Roussy was asked to give his consent before and patient consent was necessary to be enrolled in the study.

\section{Survey administration}

Copies of a self-administered questionnaire were distributed by front desk outpatient clinic staff to patients checking in for appointments with their physician at Gustave Roussy. A box 
was displayed to return the questionnaires, once completed. A member of staff was available to answer questions the patients may have. The staff was well informed about the objectives of the study. The questionnaire was distributed between June $6^{\text {th }}$ and June $14^{\text {th }}, 2013$, during seven non-consecutive days.

\section{Ethical consent}

The study received a certificate, delivered by CNIL (The French national board which enforces law on data protection) on June $4^{\text {th }}, 2013$ to guarantee personal data protection. Consent to participate was implied by the completion and return of the questionnaire. The questionnaires were fully anonymous.

\section{Analysis}

Survey data were analyzed with an optical scanner. Statistical analyses were performed using R. Results were considered significant at $\alpha=0.01$.

We first computed descriptive statistics based on survey responses. Then, an analysis based on spearman coefficients and Fisher's exact tests was conducted to investigate correlations between characteristics of patients' IBT usage and attitudes, and their age, gender, socioeconomic status, social isolation (number of people in the household), and place of living (urban/rural). For the multivariate analysis, multinomial logistic regressions were done including socioeconomic status and age as independent variables. The outcome variables for the first set of regressions was "frequency of use of mobile phone", "frequency of use of smartphone", and "frequency of use of computer". The outcome variable of the last regression was the perceived ease of use of IT devices by patients ("I feel able to use a computer, a smartphone or a tablet"). Likelihood ratio tests were conducted to ensure for the goodness of fit of the models. In the models, socioeconomic status was coded as a categorical variable. The manager category served as the reference group. 


\section{Results}

\section{Sample characteristics}

Of the 1609 questionnaires distributed, 1371 were returned. The participation level was $85 \%$.

Questionnaire with more than five missing answers were excluded from the survey. Finally, 1072 questionnaires were selected (final response rate $=67 \%$ ).

The study sample consisted of 1072 questionnaires. Respondents to the survey were 53 years old in average. $70 \%$ of them were women. Participants represented a broad spectrum of professional categories. (see Table 1)

"Insert Table 1 here"

The sample was consistent with the hospital population. As a comparison, patients coming to Gustave Roussy in 2012, had a median age of 56 years and $62 \%$ of them were women.

\section{Use}

$71 \%$ of patients used a mobile phone every day. Computers were also used on a daily basis by a majority of the study sample $(63 \%)$, or a few times a week $(21 \%)$. Tablets and smartphones were still minority but the proportion of people using it is supposed to grow quickly for a year to another. Smartphone users accounted for about $40 \%$ of the population. Most patients reported never using tablets (see Figure 1).

"Insert Figure 1 here"

$93 \%$ of our diverse population accessed the Internet from home. Among them, $68 \%$ used Internet every day. Only $7 \%$ of them didn't have access at home. 


\section{Influence of socio-demographics}

Age and employment status were significantly associated with the frequency of use of mobile phones, smartphones and computers $(p<0.05)$. The respective correlation coefficients were negative and moderate (coefficients between -0.25 et -0.49 ).

Age and employment status were then included in the logistic models.

"Insert Table 2 here"

As shown in table 2, age and employment status were predictors of the frequency of use of mobile phones, smartphones and computers. The odds of using a mobile phone or a smartphone every day rather than less than once a week decreased by $5 \%$ for one-unit increase in age. The odds of using a mobile phone every day compared to less than once a week decreased by $68 \%$ for a retired compared to a manager. The odds of using a computer every day compared to less than once a week decreased by $77 \%$ for a worker or a retired compared to a manager and by $71 \%$ for an unemployed.

\section{Intention to use IBT for health care}

Patient attitudes toward e-health activities were mainly positive. A significant majority valued the use of IBT in health care, and especially, the possibility to enhance communication with providers (see Table 3).

\section{"Insert Table 3 here"}

Communication with physicians via video was not perceived as useful by a majority of respondents $(44 \%)$. The opportunity to chat with peer patients was not seen as really important to most of them (only 44\%). Otherwise, no significant gap among attitudes between the different patient groups could be identified. 


\section{Perceived ease of use}

Above all, patients were not reluctant to use IBT. $84 \%$ of the population studied declared to be able to use a computer, a tablet or a smartphone. Only $8 \%$ disagreed.

\section{Influence of socio-demographics}

Age and employment status were significantly associated with the perceived ease of use of mobile phones, smartphones and tablets $(p<0.05)$. The respective correlation coefficients were negative and moderate (coefficients between -0.25 et -0.49 ). Age and employment status were then included in the logistic models.

"Insert Table 4 here"

As shown in table 4, Perceptions regarding the ability to use IBT devices were negatively associated with age and employment status. The odds of agreeing with the sentence "I feel able to use such devices" decreased by $7 \%$ for one-unit increase in age. The odds of feeling able to use the devices decreased by $76 \%$ for a worker, $75 \%$ for a retired, and $82 \%$ for an unemployed compared to a manager.

Except that, the only issue raised by respondents was the question of data confidentiality. A third of the population (32\%) reported being worried about this matter.

Overall, a majority of the patients included in our study sample were willing to use IBT for their health care.

\section{Discussion}

The first findings indicated that access and use of IBT were widespread in the population. These proportions align with the projections that had been made for developed countries. It is estimated that there were six billion mobile phones in 2013 , with over $85 \%$ of the world's 
population having access to a mobile signal[18]. It is less evident for tablets and smartphones (46\%) which are still used by a minority, even if the figures could change rapidly (e.g. the proportion of people owning a smartphone has doubled between 2012 and 2013 in the general population in France[19]).

The second findings were related to patient willingness to use IBT for their health. $80 \%$ of respondents considered the possibility to get an improved access to their medical records as a priority. It is something observed for other clinical conditions over the last decade[20], yet far fewer $(7 \%)$ had experience doing so[21]. We can highlight that chatting with peer patients was not necessary according to most patients (54\%) even if some blogs have been developed with success over the last decade[22].

The third findings were related to the influence of age and socioeconomic status in both access to and perceived ease of use of IBT. This measure of influence should be considered in a dynamic way (for instance, the percentage of social network users aged fifty-five to sixtyfour rose from 9 percent at the end of 2008 to 43 percent by mid-2010)[23].

\section{Challenges}

Implementation of such IBT required health care organizations to comply with standards to ensure patients a sufficient level of privacy and security when using internet-based technologies[24].

The differences in attitudes and beliefs according to patient characteristics advocate for a customized approach. This study shows that older patients are less likely to use web-based tools. As old patients are also less likely to search for information about their cancer [25],customization is necessary in order to adapt IBT to their specific needs[26].Moreover, other services can be developed to address patient preferences and provide more 
customized care such as the opportunities to schedule appointments online and to receive health-related reminders according to their specific needs.

Another challenge could consist in providers fearing that a consequence of IBT could be the cuts in hospital staffing considering the restraint number of inpatients visits. At the same time, the predictions of shortage of oncologists may alleviate the effect [1],

Last, the increase in the use of IBT can alter the doctor-patient relationship. Patients will expect providers to be much more responsive as they would need instant responses. At the same time, they will also need maintain face-to-face hospital contact[14] so the balance will be hard to find.

\section{Perspectives}

As patients are open to use them, IBT could play a significant role in cancer care coordination in the near future.

At the hospital level, IBT could offer opportunities to improve quality of care and save costs by enhancing coordination between professionals throughout the care pathway[27]. Focal points for the hospital are the possibility to reduce mails and telephone communications and to limit the number of unjustified readmissions and missed appointments (i.e. patients would not show up for a planned appointment) that are an increasing waste of time and money for both the hospital and the whole healthcare system.

At the patient level, IBT can limit the need for routine in-person outpatient visits, and monitor adverse events associated with chemotherapies. IBT can also provide reassurance by maintaining contact with the clinical team, and by providing useful information to the patients [6], [28]-[30]. They may offer additional services such as medication refills, appointment scheduling, or access to general medical information [21]. 
Another aspect of cancer care redesign could be its transition toward a patient-centered service [31]. Indeed, IBTs are effective tools to support care customization through online needs assessments and day-to-day patient follow-up via a web-based platform. It is important to notice that these web-based tools can allow a patient to access the information independently and repeatedly; the information is better readable; and the user can link the information to other sources of medical information, available on the Internet. Also, they can be adapted to the patient's wishes and knowledge level by sending e-mails through secure messaging when they want.

Last, IBTs could also be used to facilitate real-time data collection of patients' health status. Patient-driven data are becoming of paramount importance as they can provide useful information to health professionals [32].

\section{Limitations}

Limitations of this study include its sampling from a single center in a metropolitan area, so the results may have limited generalizability, although overall access and intentions were consistent with the results found in other studies made on the general population. In addition, respondents may be influenced by social desirability and be tempted to conform their answers to what is expected from them. This could affect the numbers we got in terms of willingness to use IBT in healthcare [33].

\section{Conclusion}

This study confirmed the possibility for cancer patients to use internet-based technologies for their health. No major obstacles to the development of a cancer care coordination program based on IBT could be identified. The effects of age and socioeconomic status have to be addressed. 


\section{Conflict of interest statement}

The authors declare that they have no competing interests.

\section{Acknowledgements}

The study was supported by the Foundation Philanthropia Lombard-Odier and the French National Agency for Research (ANR-MMO).

\section{References}

[1] "ASCO Report $\square$ : The state of Cancer Care in America," 2014.

[2] R. J. Kelly and T. J. Smith, "Delivering maximum clinical benefit at an affordable price: engaging stakeholders in cancer care.," The lancet oncology, vol. 15, no. 3, pp. e1128, Mar. 2014.

[3] S. B. Clauser, E. H. Wagner, E. J. Aiello Bowles, L. Tuzzio, and S. M. Greene, "Improving modern cancer care through information technology.," American journal of preventive medicine, vol. 40, no. 5 Suppl 2, pp. S198-207, May 2011.

[4] S. S. Gorin, D. Haggstrom, K. Fairfield, P. Han, P. Krebs, and S. B. Clauser, "Cancer care coordination systematic review and meta-analysis: Twenty-two years of empirical studies.," in ASCO Annual Meeting, 2013.

[5] T. Bodenheimer, E. H. Wagner, and K. Grumbach, "Improving primary care for patients with chronic illness.," JAMA : the journal of the American Medical Association, vol. 288 , no. 14 , pp. 1775-9, Oct. 2002.

[6] R. a Lewis, R. D. Neal, M. Hendry, B. France, N. H. Williams, D. Russell, D. a Hughes, I. Russell, N. S. a Stuart, D. Weller, and C. Wilkinson, "Patients' and healthcare professionals' views of cancer follow-up: systematic review.," British Journal of General Practice, vol. 59, no. 564, pp. e248-59, Jul. 2009.

[7] H. Atherton, P. Sawmynaden, A. Sheikh, A. Majeed, and J. Car, "Email for clinical communication between patients/caregivers and healthcare professionals (Review)," The Cochrane Library, no. 11, 2012.

[8] Eurostat, "Accès et Utilisation d'internet en 2013," 2013. .

[9] W. S. Chou, B. Liu, S. Post, and B. Hesse, "Health-related Internet use among cancer survivors: data from the Health Information National Trends Survey, 2003-2008," Journal of Cancer Survivorship, vol. 5, no. 3, pp. 263-270, 2011. 
[10] L. Baker, T. H. Wagner, S. Singer, and M. K. Bundorf, "Use of the Internet and E-mail for Health Care Information," Journal of American Medical association, vol. 289, no. 18, 2003.

[11] F. D. Davis, "Perceived Usefulness, Perceived Ease of Use, and User Acceptance of Information Technology," Management Information Systems Research Center, University of Minnesota, vol. 13, no. 3, pp. 319-340, 2010.

[12] G. Eysenbach, "The impact of the Internet on cancer outcomes.," CA: a cancer journal for clinicians, vol. 53, no. 6, pp. 356-71, 2003.

[13] P. R. Helft, R. E. Eckles, C. S. Johnson-Calley, and C. K. Daugherty, "Use of the internet to obtain cancer information among cancer patients at an urban county hospital.," Journal of clinical oncology: official journal of the American Society of Clinical Oncology, vol. 23, no. 22, pp. 4954-62, Aug. 2005.

[14] Y. K. Bartlett, D. L. Selby, a Newsham, a Keding, D. Forman, J. Brown, G. Velikova, and P. Wright, "Developing a useful, user-friendly website for cancer patient follow-up: users' perspectives on ease of access and usefulness.," European journal of cancer care, vol. 21, no. 6, pp. 747-57, Nov. 2012.

[15] K. Castleton, T. Fong, A. Wang-Gillam, M. a Waqar, D. B. Jeffe, L. Kehlenbrink, F. Gao, and R. Govindan, "A survey of Internet utilization among patients with cancer.," Supportive care in cancer: official journal of the Multinational Association of Supportive Care in Cancer, vol. 19, no. 8, pp. 1183-1190, 2011.

[16] R. L. Kruse, R. J. Koopman, B. J. Wakefield, D. S. Wakefield, L. E. Keplinger, S. M. Canfield, and D. R. Mehr, "Internet use by primary care patients: where is the digital divide?," Family medicine, vol. 44, no. 5, pp. 342-7, May 2012.

[17] C. K. L. Or and B.-T. Karsh, "A systematic review of patient acceptance of consumer health information technology.," Journal of the American Medical Informatics Association : JAMIA, vol. 16, no. 4, pp. 550-60, 2009.

[18] R. Kwok, "Phoning in data," Nature, vol. 458, no. April, pp. 959-961, 2009.

[19] Rapport Credoc, "La diffusion des technologies de l'information et de la communication dans la société française," 2013.

[20] S. E. Ross and C.-T. Lin, "The Effects of Promoting Patient Access to Medical Records $\square$ : A Review," Journal of the American Medical Informatics Association: JAMIA, vol. 10, no. 2, pp. 129-139, 2003.

[21] M. Turley, T. Garrido, A. Lowenthal, and Y. Y. Zhou, "Association between personal health record enrollment and patient loyalty.," The American journal of managed care, vol. 18, no. 7, pp. e248-53, Jul. 2012.

[22] E. Coiera, "Social networks, social media, and social diseases," BMJ, no. 346, p. 3007, 2013. 
[23] E. Topol, The Creative Destruction of Medicine: How the Digital Revolution Will Create Better Health Care., Basic Book. 2012, p. 303.

[24] J. L. Hall and D. McGraw, "For telehealth to succeed, privacy and security risks must be identified and addressed.," Health affairs (Project Hope), vol. 33, no. 2, pp. 216-21, Feb. 2014.

[25] C. Protière, N. Moumjid, A.-D. Bouhnik, A. G. Le Corroller Soriano, and J. P. Moatti, "Heterogeneity of cancer patient information-seeking behaviors.," Medical decision making : an international journal of the Society for Medical Decision Making, vol. 32, no. 2, pp. 362-75, 2011.

[26] E. Minvielle, M. Waelli, C. Sicotte, and J. R. Kimberly, "Managing customization in health care: A framework derived from the services sector literature.," Health policy (Amsterdam, Netherlands), Apr. 2014.

[27] Y. Y. Zhou, M. H. Kanter, J. J. Wang, and T. Garrido, "Improved quality at Kaiser Permanente through e-mail between physicians and patients.," Health affairs (Project Hope), vol. 29, no. 7, pp. 1370-5, Jul. 2010.

[28] E. M. Basch, H. T. Thaler, W. Shi, S. Yakren, and D. Schrag, "Use of information resources by patients with cancer and their companions.," Cancer, vol. 100, no. 11, pp. 2476-83, Jun. 2004.

[29] P. W. Rose and E. Watson, "What is the value of routine follow-up after diagnosis and treatment of cancer $\square$ ?," British Journal of General Practice, no. July, pp. 482-483, 2009.

[30] M. Cappiello, R. S. Cunningham, M. T. Knobf, and D. Erdos, "Breast cancer survivors: information and support after treatment.," Clinical nursing research, vol. 16, no. 4, pp. 278-93; discussion 294-301, Nov. 2007.

[31] L. H. Schwamm, "Telehealth: seven strategies to successfully implement disruptive technology and transform health care.," Health affairs (Project Hope), vol. 33, no. 2, pp. 200-6, Feb. 2014.

[32] A. K. Banerjee and S. Ingate, "Web-Based Patient-Reported Outcomes in Drug Safety and Risk Management," Drug Safety, no. 6, pp. 437-447, 2012.

[33] D. L. Paulhus, "Measurement and Control of Response Bias," in Measures of personality and social psychological attitudes, L. Wrightsman, J. Robinson, and P. Shaver, Eds. Academic Press, 1991, pp. 17-59. 
Table 1

\begin{tabular}{lc} 
Table 1. Description of respondents & Participants \\
\hline Characteristics & 53.37 \\
\hline Age & \\
Gender (\% women) & $70 \%$ \\
Women & $30 \%$ \\
Men & \\
\# of people in the household (\%) & $16 \%$ \\
1 & $36 \%$ \\
2 & $47 \%$ \\
3 et + & $1 \%$ \\
n/a & \\
Professionnal categories (\%) & \\
Retired & $26.4 \%$ \\
Manager & $22.2 \%$ \\
Worker & $21.8 \%$ \\
Unemployed & $7.4 \%$ \\
Other & $13.6 \%$ \\
n/a & $4.3 \%$ \\
Localisation (\%) & \\
Urban & $78 \%$ \\
Rural & $18 \%$ \\
n/a & $4 \%$ \\
\hline
\end{tabular}


Table 2

Table 2. Coefficients of the multinomial logistic regression on frequency of use

\begin{tabular}{lcccc}
\hline Applications & \multicolumn{2}{c}{$\begin{array}{c}\text { Frequency of use of a } \\
\text { mobile phone }\end{array}$} & $\begin{array}{c}\text { Frequency of use of a } \\
\text { smartphone }\end{array}$ \\
\hline $\begin{array}{l}\text { every day vs } \\
\text { less than } \\
\text { once/wk }\end{array}$ & $\begin{array}{c}\text { a few } \\
\text { times/wk vs } \\
\text { less than } \\
\text { once/wk }\end{array}$ & $\begin{array}{c}\text { every day vs } \\
\text { less than } \\
\text { once/wk }\end{array}$ & $\begin{array}{c}\text { a few } \\
\text { times/wk vs } \\
\text { less than } \\
\text { once/wk }\end{array}$ \\
\hline Age & $-0.05^{* *}$ & -0.02 & $-0.05^{* *}$ & $-0.05^{* *}$ \\
Employment & 1 & & & 1 \\
manager & -0.2 & -0.23 & $-0.75^{*}$ & -0.46 \\
worker & $-1.14^{*}$ & 0.3 & $-1.25^{* *}$ & 0.003 \\
retired & 0.2 & 0.9 & $-0.81^{*}$ & -0.003 \\
unemployed & \multicolumn{4}{c}{$* 0.01$} \\
\hline
\end{tabular}


Table 3

Table 3. Perceived usefulness of IBT applications

\begin{tabular}{lccc}
\hline IT applications & $\begin{array}{c}\text { useful/very } \\
\text { useful }\end{array}$ & neutral & $\begin{array}{c}\text { not useful/rather } \\
\text { not_useful }\end{array}$ \\
\hline Have access to electronic medical records & $80 \%$ & $15 \%$ \\
Fill out a self-test about your health status & $78 \%$ & $17 \%$ \\
Communicate via emails with your physician & $75 \%$ & $5 \%$ & $18 \%$ \\
$\begin{array}{l}\text { Schedule an appointment } \\
\text { Get information about disease/support }\end{array}$ & $71 \%$ & $6 \%$ & $22 \%$ \\
$\begin{array}{l}\text { Get access to external contacts (psychologist, } \\
\text { nurses...) }\end{array}$ & $69 \%$ & $12 \%$ & $18 \%$ \\
$\begin{array}{l}\text { Get help with medication monitoring (reminders, } \\
\text { side effects) } \\
\text { Give access to a relative for using these functions }\end{array}$ & $66 \%$ & $13 \%$ & $20 \%$ \\
Receive a reminder for the appointment & $48 \%$ & $12 \%$ & $26 \%$ \\
$\begin{array}{l}\text { Chat with peer patients } \\
\text { Communicate via video }\end{array}$ & $44 \%$ & $14 \%$ & $37 \%$ \\
\hline
\end{tabular}


Table 4

Table 4. Coefficients of the multinomial logistic regression on perceived ease of use

\begin{tabular}{lcc}
\hline Applications & $\begin{array}{c}\text { I am able to use a computer, a tablet, or a } \\
\text { smartphone }\end{array}$ \\
\hline & Agree vs disagree & Neutral vs disagree \\
& $-0.07^{* *}$ & -0.03 \\
\hline Age & 1 & 1 \\
$\begin{array}{l}\text { Employment } \\
\text { manager }\end{array}$ & $-1.43^{*}$ & 0.33 \\
worker & $-1.37^{*}$ & 0.27 \\
retired & $-1.7^{*}$ & 0.28 \\
unemployed & $*<0.01$ & \\
\hline & $* * 0.001$ &
\end{tabular}


Figure 1

Figure 1. Frequency of use per IT device.

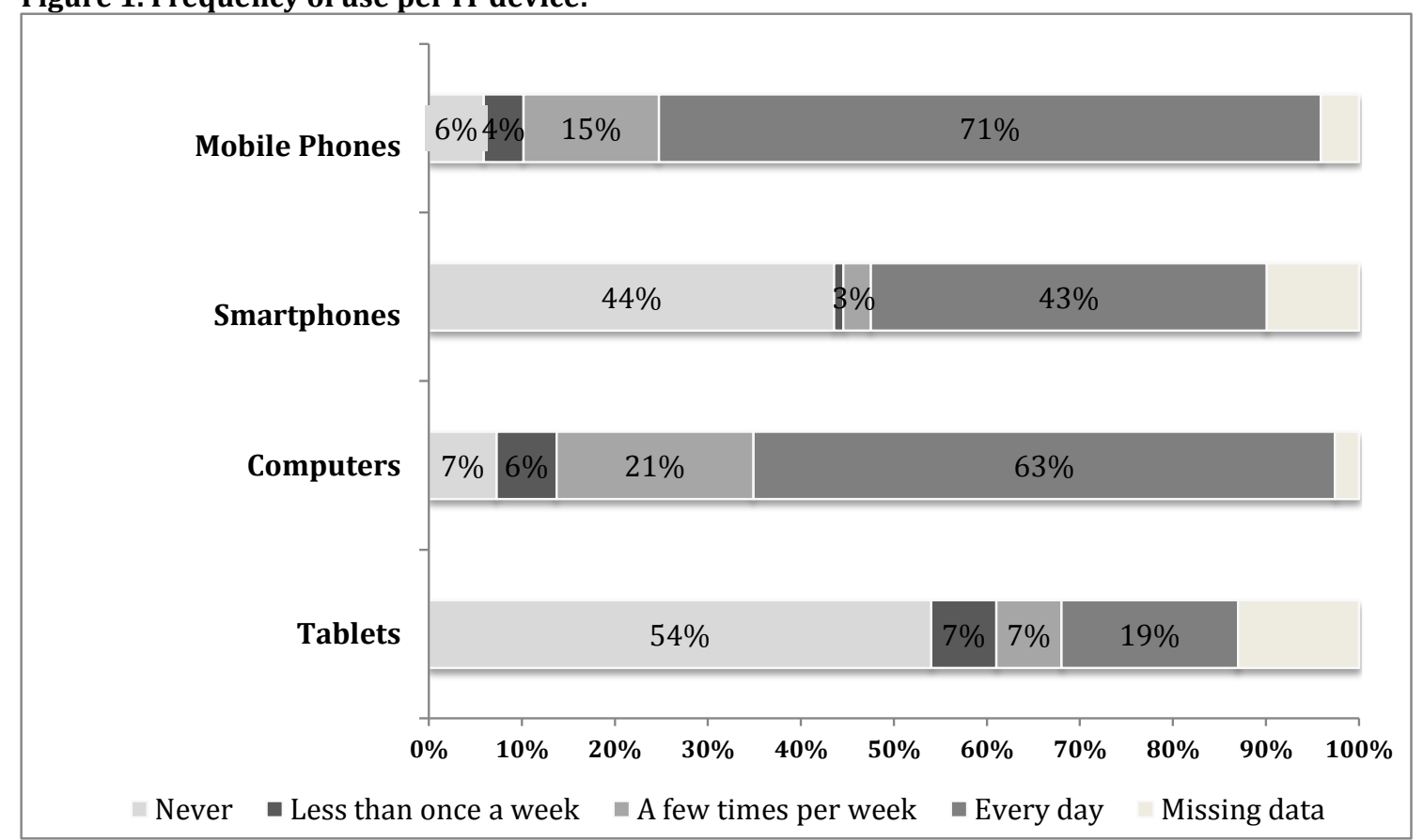

\begin{tabular}{|l|l|l|l|l|l|}
\hline & Never & Less than once a week & A few times per week & Every Day & $\begin{array}{l}\text { Missing } \\
\text { data }\end{array}$ \\
\hline Tablets & $54,00 \%$ & $7,00 \%$ & $7,00 \%$ & $19,00 \%$ & $13,00 \%$ \\
\hline Computers & $7,28 \%$ & $6,44 \%$ & $21,18 \%$ & $62,50 \%$ & $2,61 \%$ \\
\hline Smartphones & $44,00 \%$ & $1,00 \%$ & $3,00 \%$ & $43,00 \%$ & $10,00 \%$ \\
\hline $\begin{array}{l}\text { Mobile } \\
\text { phones }\end{array}$ & $5,88 \%$ & $4,29 \%$ & $14,55 \%$ & $71,18 \%$ & $4,10 \%$ \\
\hline
\end{tabular}

